Western University

Scholarship@Western

6-1-2019

Twelve tips for enhancing student engagement.

Harm Peters

Marko Zdravkovic

Manuel João Costa

Antonio Celenza

Kulsoom Ghias

See next page for additional authors

Follow this and additional works at: https://ir.lib.uwo.ca/paedpub

Part of the Pediatrics Commons 


\section{Authors}

Harm Peters, Marko Zdravkovic, Manuel João Costa, Antonio Celenza, Kulsoom Ghias, Debra Klamen, Liz Mossop, Michael Rieder, Vishna Devi Nadarajah, Danai Wangsaturaka, Martin Wohlin, and Margot Weggemans 


\section{Medical Teacher}

\section{Twelve tips for enhancing student engagement}

Harm Peters, Marko Zdravkovic, Manuel João Costa, Antonio Celenza, Kulsoom Ghias, Debra Klamen, Liz Mossop, Michael Rieder, Vishna Devi Nadarajah, Danai Wangsaturaka, Martin Wohlin \& Margot Weggemans

To cite this article: Harm Peters, Marko Zdravkovic, Manuel João Costa, Antonio Celenza, Kulsoom Ghias, Debra Klamen, Liz Mossop, Michael Rieder, Vishna Devi Nadarajah, Danai Wangsaturaka, Martin Wohlin \& Margot Weggemans (2018): Twelve tips for enhancing student engagement, Medical Teacher, DOI: 10.1080/0142159X.2018.1459530

To link to this article: https://doi.org/10.1080/0142159X.2018.1459530

册 Published online: 22 Apr 2018.

Submit your article to this journal ๘

View related articles ־

View Crossmark data $\asymp$ 


\title{
Twelve tips for enhancing student engagement
}

\author{
Harm Peters ${ }^{\mathrm{a}}$ (D, Marko Zdravkovic ${ }^{\mathrm{b} *}$, Manuel João Costa ${ }^{\mathrm{c}}$, Antonio Celenza $^{\mathrm{d}}$, Kulsoom Ghias ${ }^{\mathrm{e}}$, \\ Debra Klamen ${ }^{f}$, Liz Mossop ${ }^{g}$ (D) Michael Rieder ${ }^{h}$, Vishna Devi Nadarajahi, Danai Wangsaturakaj, \\ Martin Wohlin ${ }^{k}$ and Margot Weggemans'
}

\begin{abstract}
aDieter Scheffner Center for Medical Education and Educational Research, Deans Office of Student Affairs, Charité - Universitätsmedizin, Berlin, Germany; ${ }^{b}$ Faculty of Medicine, University of Maribor, Maribor, Slovenia; ${ }^{C}$ Life and Health Sciences Research Institute (ICVS), School of Medicine, University of Minho, Braga, Portugal; ${ }^{d}$ Education Centre, Faculty of Medicine, Dentistry and Health Sciences, University of Western Australia, Perth, Australia; 'Department of Biological and Biomedical Sciences, Aga Khan University, Karachi, Pakistan; ${ }^{\mathrm{f} S c h o o l}$ of Medicine, Southern Illinois University, Springfield, IL, USA; ${ }^{9}$ School of Veterinary Medicine and Science, University of

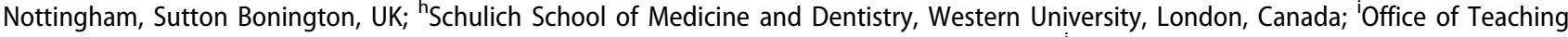
and Learning, School of Medicine, International Medical University, Kuala Lumpur, Malaysia; ${ }^{j}$ Faculty of Medicine, Chulalongkorn University, Bangkok, Thailand; ' Institution for Medical Science, Uppsala University, Uppsala, Sweden; 'Center for Research and Development of Education, University Medical Center Utrecht, Utrecht, The Netherlands
\end{abstract}

\begin{abstract}
Student engagement refers to a broad range of activities where students participate in management, education, research, and community activities within their institutions. It is a mutually beneficial collaborative approach between students and their institutions. This article provides practical advice for the implementation or further development of student engagement at medical, dental, and veterinary schools. The tips provided are based on the experiences of a group of universities recently recognized for best practice in student engagement, and are supported by evidence from the literature. The tips cover overarching themes which include the creation of an institutional culture and formal framework for student engagement, and maximize communication routes between students with peers and faculty. Tips are for specific areas of active student engagement, covering curriculum design and development, peer teaching, governance processes, research activities, peer support programs, and interaction with the local community.
\end{abstract}

\section{Introduction}

Medical education is experiencing a growing interest in student engagement. The term refers to a broad range of activities which enhance learning and professional development in students. It also helps to improve the quality of academic environment and institutional culture. While several publications introduce conceptual frameworks for student engagement (Kuh and Hu 2001; Coates 2006; Lizzio and Wilson 2009; Kahu 2013), reports which describe best practices or empirical information on the pragmatic implementation of student engagement are sparse. As many medical, dental, and veterinary schools wish to expand student engagement, the purpose of this article is to provide these institutions with practical advice on how to implement student engagement, using the experiences of an international group of universities which have been recognized to have developed a strong culture of student engagement.

In the literature, different interpretations of student engagement can be found. Traditionally, student engagement referred to the representation of students in institutional committees and their active participation in educational activities (Kuh and $\mathrm{Hu}$ 2001; Coates 2006), something that can be measured in the form of learning outcomes. Over the past decade, however, there is increasing attention toward a more comprehensive understanding of student engagement. Trowler, for example, defines student engagement as follows (Trowler 2010): "Student engagement is concerned with the interaction between the time, effort and other relevant resources invested by both students and their institutions intended to optimise the student experience and enhance the learning outcomes and development of students and the performance, and reputation of the institution."

From this definition, which we use for the purpose of this article, it becomes clear that student engagement results from a collaborative effort that should lead to mutually beneficial outcomes for students and their institutions. Beyond the traditional forms of student engagement, the term includes student participation in institutional governance and curriculum development, provision of the educational program and extracurricular courses, peer support programs as well as involvement with the academic and local communities.

Although the degree of student involvement and range of activities can vary, there are commonalities between institutions which have focused on improving student engagement. The institutional context has a great influence; what works well in one institution is no guarantee for success in another. Nonetheless, it can be very helpful to learn from institutions with a history of strong student engagement. Medical, dental, and veterinary schools that consider expanding student engagement may enhance the opportunities for more student autonomy and personal growth in already existing activities, or explore new areas in which students can be engaged in.

CONTACT Harm Peters harm.peters@charite.de D Dieter Scheffner Center for Medical Education and Educational Research, Deans Office of Student Affairs, Charité - Universitätsmedizin Berlin, Campus Charité Mitte, Charitéplatz 1, Berlin 10117, Germany

*Present address: Department of Anaesthesiology, University Medical Center Maribor, Maribor, Slovenia.

(C) 2018 Informa UK Limited, trading as Taylor \& Francis Group 
In 2012, AMEE launched the "ASPIRE initiative" (Association-for-Medical-Education-in-Europe 2013) in order to recognize excellence in student engagement, among other areas within medical education. Four spheres of engagement were defined, i.e. school management, education program, academic communities, and local community. The aim of the ASPIRE initiative is to go beyond basic accreditation standards to recognize best practices in medical, dental, and veterinary education.

For this article, universities from 12 countries over 4 continents, all recipients of the AMEE Aspire award for excellence in student engagement, have come together to build on their best practices and compile a comprehensive overview on how successful student engagement can be achieved. Experiences are supported by published literature, where available. The following twelve tips provide medical, dental, and veterinary universities (to which we refer with "universities" in the remainder of this article) and their students with practical recommendations for the implementation and further development of student engagement at their institutions.

\section{Tip 1}

\section{Create a culture that empowers students to be engaged}

An important first step toward student engagement is to create an institutional culture that empowers the students' voice and their activities. Faculty members and student representatives together should take the lead in establishing such a culture. Some faculty members may be concerned about having students as colleagues. This should be discussed in an open and candid manner, and roles need to be clearly defined (Lizzio and Wilson 2009).

As part of this process, it can be helpful to ensure that the benefits of student engagement are indeed apparent to faculty members. Students have a unique perspective on the implemented curriculum and issues that faculty may be unaware of. Using information and experiences of students will improve the quality and accountability of decisionmaking processes (Anderson 2006; Lizzio and Wilson 2009). Student engagement also leads to greater mutual respect and a collaborative approach: students gain awareness of faculty members' workload, enthusiasm, and expertise, while faculty members realize that students are acting as advocates for better educational experiences and outcomes (French et al. 2013). Furthermore, when students realize that their opinions are heard and valued, and they come to understand the reasoning behind decisions, they may show improved tolerance for unfavorable experiences and then provide constructive feedback.

\section{Tip 2}

\section{Create a framework for formal student engagement}

The way student engagement is formally organized within an institution should be made explicit in a framework that clearly explains the expected relationship between students and faculty. Such a framework should outline membership of governance and educational structures and formally list student representatives with their roles and responsibilities
(Hsih et al. 2015), describe communication pathways between students and peers and students and faculty, elaborate on the role students play in the delivery of the educational program, evaluation, and quality assurance, and explain how students contribute to the academic community and the community-at-large. In examples from ASPIRE award-winning universities, this is achieved by placing student representatives at different levels of the organization. At the lowest level, all students can report problems and suggestions to year-representatives who have regular meetings with course coordinators and other student representatives. At mid-level, there are committees for policy and education matters with both student and faculty members that have equal decision-making rights. At the highest governance level, one student dedicates a year full-time to student representation. This student is part of the management team to make sure that the student perspective is taken into account in management decisions. All students that are involved on any level meet formally on a regular basis to ensure communication and collaboration between students and an organized student voice for working with faculty and management.

\section{Tip 3}

\section{Maximize feedback in student-to-student and student- to-faculty communication}

In addition to a formal framework, an effective strategy is needed to optimize communication between students with peers and faculty. This strategy should result in closed feedback loops - it should ensure that all student voices are heard and communicated to the right faculty members, and information regarding outcomes of student engagement should be communicated back to all students. The latter is important to keep students involved because when students feel that their voices do matter, they will more likely respond to evaluation forms or provide faculty with constructive feedback for further improvement. Communication toward the student population may include formal and informal communication methods. To stay informed, some students prefer to communicate via email, while others may prefer social media, newsletters, or student meetings. The best way to find out what works for a specific student population is to simply involve student representatives in deciding which methods to use. Developing methods to reach all students prevents isolation of part of the student body (when they do not feel involved).

\section{Tip 4}

\section{Formally include student representatives in governance processes}

Students should be active stakeholders within a university governance structure. Informed advice of students advances the quality, transparency, and accountability of decision-making processes, and leads to the development of a broad set of skills for students in leadership positions. Accreditation standards often require institutions to demonstrate how the student opinion is reflected in governance decisions. Formal student engagement, however, should go beyond basic accreditation requirements where 
students are consulted on decisions which have already been made. Instead, a participatory approach should be used during the development of the university's vision, mission, policies, and values, and students should be invited to contribute to the development of the strategic direction of the university (Lizzio and Wilson 2009; Carey 2013). Such involvement requires formalized processes for the fair and transparent appointment of students to institutional committees and clear policies on their roles and responsibilities (Kahu 2013). Examples from ASPIRE award-winning universities include student representation with full voting rights on strategy-setting management boards, on policy-making, and operational curriculum committees. Through such platforms, students are involved actively in decisions pertaining to teaching, learning, assessment, faculty appointments, or fiscal planning. Strong, explicit, and genuine support of academic leadership is a driving force for enhancing this area of student engagement.

\section{Tip 5}

\section{Actively involve students in curriculum design and development}

Students have a unique perspective on the "curriculum-inaction," including the so-called hidden curriculum (Anderson 2006). Engaging with students leads to greater insight in the way students think, learn, and take decisions which may inform further improvement and development of teaching methods and materials (Anderson 2006). An additional benefit of involving students as co-producers in curricular development is that these students are in direct contact with their fellow students. Problems and concerns that arise among the student body can, therefore, be addressed directly and taken into account in the development process.

For students, active participation in educational activities has a positive effect on their academic performance. Being involved in curricular development helps to understand the (theoretical) background and structure of their curriculum. This stimulates active learning, provides insight in organizational structures, contributes to the development of a broad set of personal and professional skills, such as teamwork, leadership, and critical thinking, and leads to network expansion (Anderson 2006; Lizzio and Wilson 2009; Carey 2013). The framework for student engagement previously described in this article (Tip 2) would allow identification of students who are able to engage in this way, usually through committee representation.

\section{Tip 6}

\section{Make peer teaching part of the core curriculum}

As teaching is an important skill for future healthcare professionals, students should participate in peer teaching activities (Bulte et al. 2007; Ten Cate and Durning 2007). Moreover, peer teaching has beneficial outcomes for both the students taught by peers and the student-teachers. A closer distance between student-teachers and peers offers students a safe place to learn and ask questions. Studentteachers reach students more easily since they only recently experienced the process of acquiring knowledge or skills themselves, and may better understand their circumstances and motives (Ten Cate et al. 2012). Teaching also has a positive influence on intrinsic motivation for learning and knowledge retention of student-teachers (Ten Cate and Durning 2007). Evaluations show that both students and student-teachers highly value these peer teaching experiences (Ten Cate et al. 2012). There are a number of avenues how peer teaching can be implemented in the curriculum. It may vary from something that is optional for students who are interested in teaching, to something that is part of the core curriculum. Peer teaching requires training courses where the peer teachers are instructed on the subject and methods of teaching. These courses can be managed by faculty, students and faculty together, or even with high student autonomy and only distant oversight by the whole faculty.

Examples from the ASPIRE-winning universities encompass tutoring problem-based learning groups, teaching of and providing feedback on history taking and physical examination skills, acting as senior student-consultants for junior students in case-based clinical reasoning courses, and including an (elective) student-teaching rotation in the final year of the curriculum.

\section{Tip 7}

\section{Involve students in peer support programs}

Students should be actively involved in support programs for other students. Providing such programs is a professional approach to cope with the many challenges and hurdles that students can face. A commonly used and easily established approach is peer mentoring. For instance, senior students could act as personal, professional, and academic mentors for first years within a formal mentor program, and receive training and academic credit associated with portfolio assessment. Another approach, yet less common, can support programs where students help to increase awareness of health issues and improve healthseeking behaviors among their peers (Fares et al. 2016). Studies have shown that such supportive peer networks contribute to student well-being (Lovell 2015). Such programs can be realized in formal cooperation between students and school counseling services, but they can also be led primarily by students with support by the faculty. Overall, the aim of involvement of students in peer support programs is to the benefit of the school, and both the students giving and receiving support.

\section{Tip 8}

\section{Integrate students into the academic research community}

Institutions should provide curricular and extracurricular opportunities to integrate students into their research community. Advancing science is central to the mission and culture of many universities. An important educational aim is that students learn to understand and apply research evidence in their future professional life. Research is more than just teaching the techniques or processes. It is about engaging in communities of practice and becoming a 
contributing member. Evidence from the literature indicates that offering students an active role in research leads to positive perceptions of research, encouraging career paths as researchers, as well as contributing to the research output of the institution (Naing et al. 2015). Student research activities should be integrated into the core curriculum to acculturate all students with the practices and values of medical research by working alongside, and being mentored by faculty members. Students should be supported by the school in designing a project, joining a research group, doing the research work, and coauthoring a manuscript to get a better understanding of what it takes to participate in research and publish a peer-reviewed manuscript. Students themselves can manage student research meetings locally or at large scale. In one example from an ASPIRE award-winning university, students organize their own research conference with more than 1000 international students attending each year (European-Student'sConference 2017), thus promoting engagement across medical schools and countries. Faculty members should attend these conferences and support students' presentations at external conferences by facilitating their leave or providing financial assistance. Successful integration into the academic research community facilitates students' becoming productive members of the research community and staying engaged in future research activities.

\section{Tip 9}

\section{Demonstrate students' engagement from day one}

Universities should act as role model for student engagement from the very first day of attendance by giving current students a formal function in welcoming and introducing freshman students to the institution and study program. The multi-fold needs of incoming students can best be addressed by students who went through this process recently. Facultyand student-led activities as well as academic and nonacademic opportunities should be blended, clearly demonstrating how students and faculty members collaborate at the institution. Students should have autonomy and responsibility for at least part of the introduction. Senior students are, for example, given full autonomy over the first study week at some of the ASPIRE award-winning universities. Examples of activities where students could be engaged effectively include: introduction to local facilities, utilities, IT platforms and the curriculum, guidance on how to get organized in the new learning environment, advice on how to prepare for lessons and assessments, serving as peer mentors in the first weeks at the institution and (perhaps) new city, and introducing first years to facilities, sports clubs, community activities, and local social and nightlife. All of this leads to an initial experience that will deeply influence the future commitment of new students to their school and the student community.

\section{Tip 10}

\section{Establish support structures to facilitate student engagement}

Institutions should provide students with sufficient physical space and equipment to enable and facilitate their engagement. Students need at least a basic level of support to organize themselves and to coordinate their engagement activities. This includes facilities and related financial resources - which may span from a fully equipped building down to "pen and paper only" - that are needed for successful self-governance. In addition, students should be given access to certain parts of the institution's administration, for instance, to be able to host student material online. In turn, students should keep in mind that their individual time span as students at the university is rather short. They should create strategies which facilitate the sustainability of student engagement activities, i.e. creation of handover reports and archiving of important documents and decisions. This can be achieved for instance by setting up a good handover system, training programs for new students, and meetings with all actively involved students, so they can learn from and discuss with each other.

\section{Tip 11}

\section{Foster student engagement with the local community}

Students should be provided with ample curricular and extra-curricular opportunities to engage with the local community. There are multiple benefits of community engagement for students: increased motivation for their studies, improved confidence in communication skills, and higher awareness of the roles of other health professionals while further developing their professional identity (Dornan et al. 2006). The curricular activities can range from community health-orientated activities for junior students to clerkships within communities for more senior students (Thistlethwaite et al. 2013). Senior students on longitudinal integrated community clerkships report significant benefits of that experience for their current role as junior doctors (Birden et al. 2016). The extra-curricular engagement can include advocacy groups for vulnerable populations, fund raising for health projects, treating pets belonging to the homeless, or teaching school children about organ donation, safe sex, or risks of smoking. An example are students at one of the ASPIRE award-winning universities leading the "Adopted Village Project," where their learning is based on rural community needs and sustained by student-organized fund raising. Schools should support students in community activities by providing a variety of resources, such as money, facilities, expertise, and time in the curriculum for these activities. The investment will likely be far outweighed by an unproportionally high level of students learning and professional growth.

\section{Tip 12}

\section{Explore new opportunities for engaging students}

Institutions and students together should continue to consider new areas and approaches of actively involving students, even when a high level of student engagement is already achieved. Also in the individual feedback that the ASPIRE award-winning schools received, advice was given on areas that could be further improved in the future. Although not intended for this purpose, the ASPIRE criteria for excellence in student engagement provide a very good tool box of activities to be explored (Association-for- 
Medical-Education-in-Europe 2013). To highlight a few areas that have not been mentioned in this article so far, students can play an active teaching part or act as standardized students in faculty development courses to improve teaching skills (Gelula and Yudkowsky 2003), or develop learning resources for other students. It has become a common phenomenon that students - often groups of students - produce and share their own learning materials. In addition, students can valuably contribute to assessment and feedback. Many institutions involve forms of peer feedback in formative assessments. Others have managed to engage students in summative assessment formats such as objective structured clinical examinations (OSCEs) with reasonable quality on the assessment results (Burgess et al. 2013).

\section{Conclusions}

The implementation of student engagement can help to improve the quality of the academic environment, and enhance learning and professional development in students. Successful student engagement requires an institutional culture that empowers the students' voice and their activities, a clear framework that describes the expected relationship between students and faculty, and effective communication routes between students with peers and faculty. Once this basis is formed, students can collaborate with faculty on governmental issues, play an active role in curriculum design and development, act as peer teachers, and provide peer support for fellow students. The practical experiences that are described in this article may guide the implementation of (elements of) student engagement in other institutions.

\section{Acknowledgments}

We wish to thank the many students who helped us write this manuscript: Simon Dress, Fabian Stroben (Charité - Universitätsmedizin Berlin, Germany), Bogdan Zdravkovic (University of Maribor, Slovenia), Melanie Still and Sebastian Leathersich (University of Western Australia, Australia), Evyn Neumeister and Austin Beason (Southern Illinois University, USA), Konrad Nilsson (Uppsala University, Sweden), and Joni Remmits and Lisa Adriaansen (University Medical Center Utrecht, the Netherlands).

\section{Disclosure statement}

The authors report no conflicts of interest. The authors alone are responsible for the content and writing of the article.

\section{Notes on contributors}

Harm Peters, MD, MHPE, is a Professor of Medical Education and director of the Dieter Scheffner Center for Medical Education and Educational Research at the Charité - Universitätsmedizin Berlin, Germany.

Marko Zdravkovic, MD, is a teaching assistant and former coordinator of Centre for Medical Education at Faculty of Medicine, University of Maribor, and an anesthesiology resident at University Medical Centre, Maribor, Slovenia.

Manuel João Costa, PhD, is an Associate Professor and coordinator of the Medical Education Unit at the School of Medicine, University of Minho, Portugal.

Antony Celenza, MBBS, MclinEd, University of Western Australia is a Professor of Medical Education and Emergency Medicine and Head of the MD Program and MD Education Unit.
Kulsoom Ghias, PhD, is an Associate Professor in the Department of Biological and Biomedical Sciences and co-chair of the Undergraduate Medical Curriculum Committee at the Aga Khan University in Karachi, Pakistan.

Debra Klamen, MD, MHPE, is a Professor and chair of the Department of Medical Education and senior associate dean for Education and Curriculum at the Southern Illinois University School of Medicine, USA. Liz Mossop, PhD, is a Professor of Veterinary Education at the School of Veterinary Medicine and Science University of Nottingham, UK.

Michael Rieder, MD, PhD, is chair of the Department of Paediatrics and was the Assistant dean for Learner Equity and Wellness (Undergraduate Student Affairs), Schulich School of Medicine \& Dentistry Western University, Canada.

Vishna Devi Nadarajah, PhD, MHPE, is a Professor of Human Biology in the School of Medicine and dean of Teaching and Learning at the International Medical University, Malaysia.

Danai Wangsaturaka, MD, PhD, is a lecturer in medical education and assistant dean of Academic Affairs at Faculty of Medicine, Chulalongkorn University, Thailand.

Martin Wohlin, MD, PhD, MD, PhD, is a Senior Lecturer in Emergency Medicine, former Head of the Unit for Medical Education, Uppsala University, Sweden.

Margot Weggemans, MD, is a PhD candidate at the Center for Research and Development of Education, University Medical Center Utrecht, the Netherlands.

\section{ORCID}

Harm Peters (iD) http://orcid.org/0000-0003-1441-7512

Liz Mossop (D) http://orcid.org/0000-0003-1317-1856

\section{References}

Anderson I. 2006. Student representation in managing the medical curriculum. Clin Teach. 3:154-157.

Association-for-Medical-Education-in-Europe. 2013. Aspire International Recognition of Excellence in Education. [accessed 2017 Oct 10]. http://www.aspire-to-excellence.org

Birden H, Barker J, Wilson I. 2016. Effectiveness of a rural longitudinal integrated clerkship in preparing medical students for internship. Med Teach. 38:946-956.

Bulte C, Betts A, Garner K, Durning S. 2007. Student teaching: views of student near-peer teachers and learners. Med Teach. 29:583-590.

Burgess A, Clark T, Chapman R, Mellis C. 2013. Senior medical students as peer examiners in an OSCE. Med Teach. 35:58-62.

Carey P. 2013. Student engagement: stakeholder perspectives on course representation in university governance. Stud High Educ. 38:1290-1304.

Coates H. 2006. The value of student engagement for higher education quality assurance. Qual High Educ.11:25.

Dornan T, Littlewood S, Margolis SA, Scherpbier A, Spencer J, Ypinazar V. 2006. How can experience in clinical and community settings contribute to early medical education? A BEME systematic review. Med Teach. 28:3-18.

European-Student's-Conference. 2017. [accessed 2017 Oct 10]. http:// www.esc-berlin.com

Fares J, Al Tabosh H, Saadeddin Z, El Mouhayyar C, Aridi H. 2016. Stress, burnout and coping strategies in preclinical medical students. North Am J Med Sci. 8:75-81.

French JC, Bickett MM, locono JA. 2013. Sifting through course evaluations: medical student comments driving surgery curriculum changes. J Surg Educ. 70:368-372.

Gelula MH, Yudkowsky R. 2003. Using standardised students in faculty development workshops to improve clinical teaching skills. Med Educ. 37:621-629.

Hsih KW, Iscoe MS, Lupton JR, Mains TE, Nayar SK, Orlando MS, Shenderov K. 2015. The student curriculum review team: how we catalyze curricular changes through a student-centered approach. Med Teach. 37:1008-1012.

Kahu ER. 2013. Framing student engagement in higher education. Stud High Educ. 38:758-773. 
Kuh GD, Hu S. 2001. The effect of student-faculty interaction in the 1990s. Rev High Educ. 24:309-332.

Lizzio A, Wilson K. 2009. Student participation in university governance: the role conceptions and sense of efficacy of student representatives on departmental committees. Stud High Educ. 34:69-84.

Lovell B. 2015. 'We are a tight community': social groups and social identity in medical undergraduates. Med Educ. 49:1016-1027.

Naing C, Wai VN, Durham J, Whittaker MA, Win NN, Aung K, Mak JW. 2015. A systematic review and meta-analysis of medical students' perspectives on the engagement in research. Medicine (Baltimore). 94:e1089.
Ten Cate O, Durning S. 2007. Peer teaching in medical education: twelve reasons to move from theory to practice. Med Teach. 29:591-599.

Ten Cate O, Van de Vorst I, Van den Broek S. 2012. Academic achievement of students tutored by near-peers. Int J Med Educ. 3:6-13.

Thistlethwaite JE, Bartle E, Chong AA, Dick ML, King D, Mahoney S, Papinczak T, Tucker G. 2013. A review of longitudinal community and hospital placements in medical education: BEME Guide No. 26. Med Teach. 35:e1340-e1364.

Trowler V. 2010. Student engagement literature review. High Educ Acad. 11:1-15. 